\title{
Turning Problems into Opportunities: How to Resume Urological Elective Surgery Using a Scoring System during COVID-19 Outbreak
}

\section{Convirtiendo problemas en oportunidades: como reanudar la cirugía urológica electiva utilizando un sistema de puntaje durante la pandemia por COVID-19}

\author{
Julian Chavarriaga ${ }^{1}$ Hugo Lopez-Ramos ${ }^{1}$ Juan Prada ${ }^{1}$ Nicolas Fernandez ${ }^{1,2}$ \\ ${ }^{1}$ Division of Urology, Hospital Universitario San Ignacio, Pontificia \\ Universidad Javeriana, Bogotá, Colombia \\ ${ }^{2}$ Division of Urology, Seattle Children's Hospital, Seattle, WA, United States \\ Address for correspondence Julian Chavarriaga, MD, División de \\ Urología, Hospital Universitario San Ignacio, Pontificia Universidad \\ Javeriana, Carrera 7 No. 40-62. Bogotá., Colombia \\ (e-mail: chavarriagaj@javeriana.edu.co).
}

Urol Colomb 2021;30(4):e271-e276.

\begin{abstract}
Objective Severe acute respiratory syndrome coronavirus-2 (SARS-CoV-2) causes coronavirus disease 2019 (COVID-19), which is the largest pandemic in the last century and has created a health care crisis worldwide. Contingency plans have led to put on hold all urological elective surgeries. The aim of the present article is to report the adaptation of the Medically Necessary Time-Sensitive (MeNTS) scoring system to triage patients who were awaiting urological elective surgery during the COVID-19 pandemic. Methods The present study was conducted as a part of a necessary transition of care delivery at a tertiary care institution in order to re-establish urological elective surgery. We triaged all urological elective surgeries with the MeNTS instrument and proposed a cutoff value of 45 points to avoid complications in the COVID-19 crisis while resuming elective procedures.

Results A total of 91 patients awaiting elective urological surgery pending to be rescheduled were identified. Their median age was 60.5 years old (interquartile range [IQR]: 46-93). Twenty-five patients were American Society of Anesthesiologists (ASA)

Keywords

- coronaviruses

- COVID-19

- surgical procedure

- pandemic

- urological surgical procedure

- SARS-CoV-2 infection class I, 51 (56\%) were class II, and 12 (13\%) were class III. The median MeNTS score was 42 points (IQR: $36-59)$. Twenty-nine patients had a MeNTS score $>45$ and were advised to postpone their surgery. Sixty-two had a score $\leq 45$ and were gradually rescheduled. Conclusions The present study may have practical implications regarding the selection of urological elective surgeries in the challenging health care situation caused by the COVID-19 pandemic. Our real-life data showed us that $32 \%$ of our procedures must be postponed, and $68 \%$ could be carefully considered and gradually rescheduled for surgery.
\end{abstract}

received

January 22, 2021

accepted

July 2, 2021

published online

August 13, 2021
DOI https://doi.org/

10.1055/s-0041-1733841.

ISSN 0120-789X.

e ISSN 2027-0119.
(C) 2021. Sociedad Colombiana de Urología. All rights reserved. This is an open access article published by Thieme under the terms of the Creative Commons Attribution-NonDerivative-NonCommercial-License, permitting copying and reproduction so long as the original work is given appropriate credit. Contents may not be used for commercial purposes, or adapted, remixed, transformed or built upon. (https://creativecommons.org/ licenses/by-nc-nd/4.0/)

Thieme Revinter Publicações Ltda., Rua do Matoso 170, Rio de Janeiro, RJ, CEP 20270-135, Brazil 


\section{Resumen}

Palabras Clave
- coronavirus
- COVID-19
- procedimiento
quirúrgico
- pandemia
- procedimiento
quirúrgico urológico
- infección por SARS-
CoV-2

Introducción El coronavirus del síndrome de dificultad respiratoria aguda 2 (severe acute respiratory syndrome coronavirus 2, SARS-CoV-2, en inglés) causa la llamada enfermedad por coronavirus 2019 (coronavirus disease 2019, COVID-19, en inglés) que ha generado la pandemia más grande en el último siglo, y ha llevado a una crisis en el sistema de salud a nivel mundial. El objetivo de este artículo es reportar la utilización del sistema médicamente necesario, sensible al tiempo (medically necessary, timesensitive, MeNTS, en inglés) para gradualmente reanudar la cirugía urológica programada durante la pandemia.

Metodos Este estudio se llevó a cabo como parte de una transición necesaria en la atención en salud para restablecer la cirugía urológica programada. Clasificamos a todos los pacientes utilizando el instrumento MeNTS, y arbitrariamente propusimos un punto de corte de 45 puntos, dinámico de acuerdo con el momento y la situación de la pandemia.

Resultados Un total de 91 pacientes en espera de cirugía urológica programada fueron identificados. La mediana de edad fue de 60.5 años (rango intercuartil [RIC]: 46 a 93 años). En total, 25 (27.4\%) pacientes eran clase I en la clasificación de la Sociedad Americana de Anestesiólogos (American Society of Anesthesiologists, ASA), 51 (56\%) eran ASA II, y 12 (13\%), ASA III. La mediana del puntaje del MeNTS fue de 42 puntos (RIC: 36 a 59). En total, 29 pacientes tuvieron un puntaje de MeNTS mayor a 45 puntos, y se les recomendó posponer su cirugía electiva; 62 (68\%) tuvieron un puntaje $\leq 45$ puntos, y se reprogramaron gradualmente a partir del $1^{\text {ro }}$ de mayo de 2020.

Conclusiones Este estudio puede tener varias implicaciones practicas a la hora de seleccionar pacientes para reprogramar su cirugía urológica electiva durante situaciones desafiantes para los sistemas de salud, como la pandemia por COVID-19. Nuestros datos de la práctica clínica real muestran que el $32 \%$ de los procedimientos se deben posponer, y el $68 \%$ pueden considerarse cuidadosamente para ser reprogramados gradualmente.

\section{Introduction}

Severe acute respiratory syndrome coronavirus 2 (SARSCoV-2) causes coronavirus disease 2019 (COVID-19), which is characterized by influenza-like illness (ILI) (fever, cough, sore throat, body aches, and dyspnea). In severe cases, it can cause SARS with a high chance of needing mechanical ventilation. ${ }^{1-4}$ The rapid spreading of the virus has generated a health crisis worldwide, and health resources have had be reallocated to treat COVID-19 patients.

Currently, the Centers for Disease Control and Prevention (CDC) has a Pandemic Intervals Framework (PIF) to track the phases of an influenza pandemic. This framework is being applied to COVID-19. The PIF described 6 pandemic intervals: 1) Investigation of cases of novel SARS-CoV-2 in humans; 2) recognition of increased potential for ongoing transmission of the virus; 3 ) initiation of a pandemic wave; 4) acceleration of the pandemic wave, which is the upward epidemiological curve as the new virus infects susceptible people; 5) deceleration of a pandemic wave, which happens when pandemic COVID-19 cases consistently decrease; and 6) preparation for future pandemic waves. ${ }^{5,6}$

The impact on urology practice has created a need to cancel elective surgery to avoid the risk of virus transmission to healthcare practitioners and patients and to spare personal protection equipment (PPE). Also, these restrictive measures try to reduce the need for occupation of intensive care unit (ICU) beds. ${ }^{1,4,7,8}$ With the exception of oncological cases, most elective urological surgeries could be postponed without a negative impact on the prognosis of the patient. There is a tendency to commingle the terms "elective" and "optional" when it comes to surgical procedures. Elective could be interpreted as the fact that the acuity of the condition allows to find a preferable timing to schedule the procedure without comprising the surgical outcomes or the prognosis of the condition to be treated. Except for purely aesthetic procedures, there is always a rationale to find a time-sensitive framework to resume "elective" procedures. ${ }^{9}$ It is very important in our field, given that despite most surgical procedures could be postponed without a major impact on the health of patients, the waiting list to be scheduled for surgery could be considerable in some countries, which adds to the fact that we having had to cancel their surgery due to the COVID-19 crisis could lead to undesirable outcomes. $^{10}$

It is necessary to find an objective and practical system to start rescheduling urological elective procedures in the deceleration phase of the pandemic. ${ }^{4,7}$ The aim of the present article is to report the adaptation of the Medically Necessary Time-Sensitive (MeNTS) scoring system to triage patients waiting to be operated during the COVID-19 pandemic. ${ }^{9}$ Our results will help to gradually resume elective 
urological surgery without comprising hospital resources and the safety of healthcare workers and patients.

\section{Methods}

The present study was conducted as a part of a transition plan at a tertiary care institution aiming to re-establish urological elective surgeries. After Internal Review Board (IRB) approval, we used MeNTS, which has been developed by Pranchand et al., ${ }^{9}$ as a novel scoring system to prioritize medically necessary operations that should not be delayed due to the COVID-19 pandemic. ${ }^{9}$ The MeNTS scoring system comprehends 21 plausible factors contributing to poorer perioperative outcomes, risk of SARS-CoV2 transmission to health care professionals, and increased hospital resource utilization during the pandemic, with value anchors assigned to a scale ranging from 1 to 5 based on objective measures. ${ }^{9}$ The score contains 3 domains: procedure, patient, and disease, each of which gets a score $(7-35 ; 6-30$; and 8-40, respectively), and the total score, ranging from 21 to 105 , is computed for each case. ${ }^{9}$ The higher the score, the greater the risk to the patient, or the need for health system resources. Also, high scores correlate with higher chances of COVID-19 transmission to healthcare professionals. ${ }^{9}$

The Spanish surgical association (AEC, in the Spanish acronym) published their guidelines on how to resume elective surgery in their country after the peak of the pandemic had passed. They used the Pranchand scoring system but set a cutoff value $\geq 55$ to reconsider patients for elective surgery. ${ }^{9}$ Considering the socioeconomic situation of our patients, waiting times, as well as our hospital infrastructure and pandemic trend predictions, we decided arbitrarily to establish a cutoff value $\geq 45$ points to postpone surgical procedures. Considering that there are 80 points between 21 and 105 (minimum and maximum score), the mean value would be 65 points, and considering that $25 \%$ of the 80 points would be 20 , we deducted 20 points from the mean value and got a cutoff value of 45 to avoid the maximum number of complications in the COVID-19 crisis. The threshold value to schedule surgery was dynamically modified according to the resources available, to the COVID-19 active cases, and to the availability of ICU beds.

All cases were evaluated on an individual basis. An electronical database of all patients waiting for urological elective surgery was built, and the American Society of Anesthesiologists (ASA) class was calculated based on preoperative anesthesia consultations. The MeNTS scoring system was applied to each patient considering their comorbidities and using a previously assigned standardized value to each surgery.

When calculating the MeNTS score, we established a predefined score to each procedure in a general meeting of the Urology division. For example, for transurethral resection of the prostate (TURP), we assigned 60 to 120 minutes of operating room (OR) time (scoring 3 points), an estimated length of hospital stay of 24 to 48 hours ( 3 points), a need of postoperative ICU $<5 \%$ ( 2 points), an anticipated blood loss of 250 to $500 \mathrm{ml}$ ( 3 points), 2 members of the surgical team ( 2 points), intubation probability of 1 to $5 \%$ ( 2 points), and surgical site, endoscopic so none of the following was chosen ( 1 point) Procedure factors score $=16$ points. For disease factors for benign prostatic obstruction (BPO), which was the case in TURP, nonoperative treatment effectiveness we assigned $60-95 \%$ as effective as surgery ( 3 points), nonoperative treatment resource/exposure risk, equivalent (3 points), impact of 2 week delay in disease outcome and in surgical risk, no worse in both (5 points each), impact of 6 week delay in disease outcome and in surgical risk, no worse for both (3 points each); Disease factors total score was 27. Every patient who was awaiting TURP elective surgery would start the scoring system with 38 points.

Patients were questioned regarding the presence of ILI symptoms and exposure to known COVID-19-positive people in the previous 2 weeks. In the first phase of our study, all patients were assumed to have been possibly in contact with COVID-19 (scoring 3 points); therefore, SARS-CoV-2 realtime polymerase chain reaction (PCR) diagnostic tests were initially reserved only for symptomatic patients. After reverse transcription loop-mediated isothermal amplification (RT-LAMP) assays to detect genomic ribonucleic acid (RNA) of SARS-CoV-2 were approved by the FDA and available in our country, all patients undergoing major surgeries that required in-patient care were instructed to be tested prior to elective surgery.

The authors have obtained informed consent of the patients or the subjects involved in this manuscript. This documents are kept by the corresponding author.

\section{Statistical Analysis}

Descriptive analysis, proportions, central tendency (median and mean), and dispersion (standard deviation [SD], interquartile range [IQR]) measures were used. The COVID-19 MeNTS score was calculated with Microsoft Excel Version 2020 (Microsoft Corporation, Redmond, WA, USA). STATA V.14.0 (StataCorp, College Station, TX, USA) was used for statistical calculations.

\section{Results}

On March 6, 2020, the first confirmed SARS-CoV2 case was reported in Colombia. On March 24, the government declared a mandatory lockdown at a national level. All urological scheduled elective surgeries were canceled at that moment. Two months later, all pending elective surgeries were reviewed, and we found a total of 91 patients waiting for elective surgery. Their median age was 60.5 years old (IQR: 46-93), 25 (27.4\%) patients were ASA class I, 51 (56\%) were ASA class II, and 12 (13\%) were ASA class III.

The median MeNTS score in our cohort was 42 points (IQR: 36-59). Twenty-nine patients had a MeNTS score $>45$ points and were advised to postpone surgery. Sixty-two had a score $\leq 45$ and were gradually scheduled for urological elective surgery. (-Fig. 1.)

Fourteen patients were scheduled for open or endoscopic prostatectomy, and 22 for endourological surgery, of which 14 were scheduled for percutaneous nephrolithotomy 


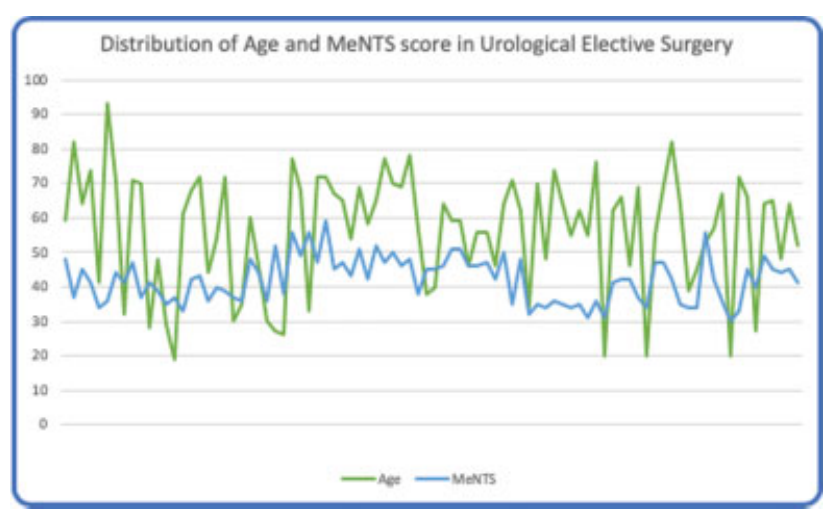

Fig. 1 Distribution of age (years old) and MeNTS score (points) in patients awaiting urological elective surgery.

(PCNL) and 8 for retrograde intrarenal surgery (RIRS). A total of 21 patients had reconstructive urological conditions, of which 9 were scheduled for urethroplasty or direct vision internal urethrotomy (DVIU). Six were scheduled for prosthetic surgery, and three for sex affirming surgery. Eight patients were scheduled for circumcision, four for tension free vaginal tapes (TVT), and the rest for miscellaneous urological procedures. Urological oncology elective surgeries were not triaged only with the MeNTS scoring system, which is why they were not included in the present report. (-Table 1.)

Five (5.4\%) of our patients had lung disease as a comorbidity (asthma, chronic obstructive pulmonary disease [COPD] or cystic fibrosis). Four (4.3\%) had obstructive sleep apnea (OSA) and 43 had cardiovascular disease, of which 29 had hypertension and 14 had cardiac heart failure (CHF) or coronary artery disease (CAD). Ten patients were diabetic, and none were immunocompromised. Results are shown on - Table 1.

The patients were always informed about the risk of SARS$\mathrm{CoV}-2$ infection during their elective surgery and agreed to undergo surgery knowing the potential risks and associated complications. We intended to have the shortest possible length of hospital stay in all postoperative patients. All measures were taken to prevent SARS-CoV-2 transmission, such as independent and individual access to the ORs, independent elevators for moving patients scheduled for elective surgery, specific and isolated ORs for COVID-19 patients, limited time in the recovery room, and specific wards for surgical patients free of COVID-19. Finally, the postoperative control was scheduled for 3 to 4 weeks after surgery to prevent unnecessary displacements. Urethral catheters were removed as soon as possible, Double-J stents were always left with strings for outpatient removal. Early recovery after surgery (ERAS) protocols were encouraged. For laparoscopic surgeries, we used trocars with one-way valves and connected the smoke evacuator to one of the ports and set a pneumoperitoneum pressure of $12 \mathrm{mmHg} .{ }^{11,12}$

\section{Discussion}

The MeNTS instrument developed by Pranchand et al. at the Department of Surgery of the Chicago University is a valuable tool and should be considered as one of the steps to resume elective surgery in our field. ${ }^{9}$ Our experience showed us that it is a simple, uncomplicated scoring system, easy to understand, and that could be applied straightforwardly to triage urological surgeries, avoiding unnecessary risks. It is recommended to calculate the cumulative MeNTS score and set a threshold that could be dynamically adjusted to respond to the immediate and anticipated availability of resources and local conditions. Performing a procedure whose score exceeds the upper threshold of the MeNTS score. Is unlikely to be justifiable given the associated risks and a lower threshold MeNTS score can be assigned to surgery, below which it would be reasonable to proceed with MeNTS procedures while reserving the $\mathrm{OR}$ for highly urgent cases. ${ }^{13}$ To asses concordance of the MeNTS cases permitted during cessation of elective surgery, Prachand et $\mathrm{al}^{9}$, calculated the MeNTS cumulative scores of a broad range of surgical specialties, including general surgery, surgical oncology, otorhinolaryngology, neurosurgery, vascular surgery, urology, and plastic surgery, and the process was suggestive of relative concordance with the ad hoc decisions made prior to the creation of the MeNTS. ${ }^{13}$

At the time the present article was written, we had set a threshold of 45 points, and we found that $32 \%$ of the patients scheduled for surgery should be reconsidered and reassured

Table 1 Clinical characteristics

\begin{tabular}{|l|l|l|l|l|l|}
\hline Comorbidities & $n$ & Age (years old) & ASA class & MeNTS (points) & Reconsider surgery \\
\hline Diabetes & 10 & $62(59-72)$ & II (8), III (2) & 46.9 & $7(70 \%)$ \\
\hline Cardiovascular disease & 43 & \multicolumn{5}{|l|}{} \\
\hline 1. CAD/ CHF & 14 & $69(64-82)$ & II (9), III (5) & 41.4 & $1(7 \%)$ \\
\hline 2. Hypertension & 29 & $68(65-93)$ & II (23), III (6) & 44 & $13(45 \%)$ \\
\hline Lung Disease (COPD, asthma) & 5 & $71.5(66-82)$ & II (5) III (1) & 45.6 & $3(50 \%)$ \\
\hline OSA & 4 & $67(59-78)$ & II (3), III (1) & 54.7 & $4(100 \%)$ \\
\hline Total & 91 & $60.5(46-93)$ & I (25), II (51), III12 & 83 & $29(32 \%)$ \\
\hline
\end{tabular}

Abbreviations: ASA, American Society of Anesthesiologists; CAD, coronary artery disease; CHF, congestive heart failure; CPOD, chronic obstructive pulmonary disease; MeNTS, Medically Necessary Time-Sensitive scoring system; OSA, obstructive sleep apnea.

${ }^{* *}$ Values are reported as median and interquartile range for age and as mean for MeNTS score. 
given that the risk of undergoing surgery was greater than the benefits for them and for the healthcare practitioners. We also let the patients know that, as soon as the phases of the pandemic are shifting toward recovery, they must be screened for SARS-CoV-2 and that, according to the availability of resources and to local conditions, the MeNTS threshold could be dynamically reset and they could be scheduled for the procedure. At present, decisions of resuming surgery are being made on a case-by-case basis, with urologists following guidelines developed by the European Association of Urology (EAU) and the American Urological Association (AUA), among others. ${ }^{8}$ Hospitals must make sure they can care for the influx of patients who have severe or critical SARS-CoV-2 infection and may require ICU beds. ${ }^{7}$ Hospitals must also ensure that physicians, nurses, and other staff are not subjected to unnecessary risks of infection. ${ }^{7}$ Urological patients still need surgical care that should not be delayed for an excessive amount of time.

Campi et al. reported, in their multicentric study, the insights obtained from the strategies of three ${ }^{14}$ Italian urological oncology high-volume referral centers to guide prioritization during the COVID-19 pandemic.(21) They reported that, in times of emergencies that lead to OR availability shortage for urologic procedures, $67.8 \%$ of elective major uro-oncologic surgeries could be postponed and $32.2 \%$ of the patients could not be postponed, and that a nonnegligible percentage of patients could be shifted to alternative treatment strategies after shared decision-making. ${ }^{15}$ For urological oncologic procedures, we proceed to operate nondeferrable surgeries according to the EAU COVID 19 Recommendations, during the time our study was conducted we performed one laparoscopic radical nephroureterectomy, four laparoscopic radical nephrectomies in CT2B renal cell carcinomas, one radical cystectomy with an ileal conduit and extended pelvic lymph node dissection (ePLND), and one ilioinguinal lymph node dissection (ILND) in a patient with penile squamous cell carcinoma (SCC). For laparoscopic cases, we followed the recommendations of Zampolli et al. ${ }^{15}$

Simonato et al. ${ }^{16}$ published a set of recommendations and pathways of pre-, intra- and postoperative care for urological patients undergoing elective and nondeferrable interventions during the COVID-19 pandemic. ${ }^{16}$ Among their recommendations, they advise an accurate triage for ILI symptoms by telephone in order to provide as many instructions to the patients to facilitate their return to and stay at home, and proposed reducing or rescheduling postdischarge controls and implementing an adequate communications system for telemonitoring discharged patients to reduce hospital visits. ${ }^{7}$ After extensively reviewing the current literature regarding COVID-19 screening, we found that this is an acceptable strategy, and that is the reason why we implemented it. ${ }^{7}$ Specifically, pathways for elective surgery were given, which recommend to try to perform these elective procedures in COVID-19-free hospital. During the preadmission phase, it is necessary to carry out a nasopharyngeal swab test in all patients to rule out the presence of the SARS-CoV-2, and after the test comes back negative, the patient should be sent directly to the OR ward, guarantying a single access point.
Another aid is to reduce the number of beds per room and to ensure a minimum safety distance between patients. ${ }^{7}$ Regarding laparoscopic surgery, the aforementioned guidelines advise against them or to perform them with extreme caution in order to minimize the risk of viral contagion to the operating staff; the use of a device for suction of surgical smoke produced by the electrocautery during open surgery and during laparoscopy should be considered. ${ }^{7}$

An objective scoring system may not be necessary to know that prosthetic, gender affirming surgery, and inguinoscrotal surgery could be delayed indefinitely. Also, the pace of reopening ORs is highly dependent upon the status of COVID-19 in each country and hospital. The recommendations and findings of the present study may not be generalizable to other countries or hospitals, but we believe they shed a light of hope in gradually reestablishing urologic elective surgery and show our experience with this scoring system, which could be tailored to every country and hospital needs and dynamically set through different moments during this pandemic.

The strengths of our study are the report of our experience with the MeNTS cumulative score within a specialized urological center throughout the largest pandemic in the last century, as well as the description of the impact of the questionnaire and its score and dynamic threshold points to aid in surgical rescheduling decision-making. Our study has several limitations, namely, its retrospective and unicentric nature, the fact that there was not a standardized threshold value for the MeNTS cumulative score, and that we arbitrarily decided to establish a cutoff value of $\geq 45$ points to consider postponing surgical procedures and changed it dynamically according to the moment of the pandemic. Another limitation is that some patients were not initially screened with SARS-CoV-2 RT-PCR diagnostic test, given the lack of availability of the tests at the beginning of the COVID19 outbreak in our country.

\section{Conclusions}

The COVID-19 pandemic has changed the way we live, treat our patients, and relate to each other. Urological elective surgery has suffered a major blow to safekeep the well-being of our patients and healthcare practitioners. We proposed the implementation of the MeNTS scoring system to triage urological elective procedures and patients and to resume our clinical practice in a safe and objective manner, considering factors regarding hospital resources, patients, procedures, and disease. Overall, the present study may have practical implications, considering that the selection of urological elective surgeries in the challenging healthcare situation caused by the COVID-19 pandemic is crucial and that our real-life data showed us that $32 \%$ of our procedures must be postponed and $68 \%$ could be carefully reconsidered and gradually scheduled.

Responsabilidades Éticas

Protección de personas y animales. Los autores declaran que los procedimientos seguidos se conformaron a las 
normas éticas del comité de experimentación humana responsable y de acuerdo con la Asociación Médica Mundial y la Declaración de Helsinki.

Confidencialidad de los datos. Los autores declaran que han seguido los protocolos de su centro de trabajo sobre la publicación de datos de pacientes.

Derecho a la privacidad y consentimiento informado. Los autores han obtenido el consentimiento informado de los pacientes y/o sujetos referidos en el artículo. Este documento obra en poder del autor de correspondencia.

Conflict of Interests

The authors have no conflict of interests to declare.

\section{References}

1 Zhu N, Zhang D, Wang WChina Novel Coronavirus Investigating and Research Team. et al; A Novel Coronavirus from Patients with Pneumonia in China, 2019. N Engl J Med 2020;382(08):727-733

2 Lipsitch M, Swerdlow DL, Finelli L. Defining the epidemiology of Covid-19 - Studies needed. New England Journal of Medicine 2020;382(13):1194-1196

3 Lipsitch M, Swerdlow DL, Finelli L. Defining the Epidemiology of Covid-19 - Studies Needed. N Engl J Med 2020;382(13):1194-1196

4 Puliatti S, Eissa A, Eissa R, et al. COVID-19 and urology: a comprehensive review of the literature. BJU Int 2020;125(06): E7-E14

5 Qualls N, Levitt A, Kanade N, et al; CDC Community Mitigation Guidelines Work Group. Community Mitigation Guidelines to Prevent Pandemic Influenza - United States, 2017. MMWR Recomm Rep 2017;66(01):1-34

6 Holloway R, Rasmussen SA, Zaza S, Cox NJ, Jernigan DB. Updated preparedness and response framework for influenza pandemics. MMWR Recomm Rep 2014;63(RR-06):1-18

7 Ficarra V, Novara G, Abrate A, Bartoletti R, Crestani A, De Nunzio C, et al. Urology practice during COVID-19 pandemic. Minerva
Urologica e Nefrologica - The Italian Journal of Urology and Nephrology 2020;72(03):369-375

8 Considerations G. Centers for Medicare \& Medicaid Services (CMS) Recommendations Re-opening Facilities to Provide Nonemergent Non-COVID-19 Healthcare. Phase 2020;I:1-3. Available at: https://www.cms.gov/files/document/covid-flexibility-reopen-essential-non-covid-services.pdf

9 Prachand VN, Milner R, Angelos P, et al. Medically Necessary, Time-Sensitive Procedures: Scoring System to Ethically and Efficiently Manage Resource Scarcity and Provider Risk During the COVID-19 Pandemic. J Am Coll Surg 2020;231(02):281-288

10 Iscaife A, Marchini GS, Srougi V, et al. The urologist's role in the fight of COVID-19 pandemic: mandatory mindset shift on the frontline. Int Braz J Urol 2020;46(05):879-882

11 Stensland KD, Morgan TM, Moinzadeh A, et al. Considerations in the Triage of Urologic Surgeries During the COVID-19 Pandemic. Eur Urol 2020;77(06):663-666. Doi: 10.1016/j.eururo. 2020.03.027

12 Vigneswaran Y, Prachand VN, Posner MC, Matthews JB, Hussain M. What Is the Appropriate Use of Laparoscopy over Open Procedures in the Current COVID-19 Climate? J Gastrointest Surg 2020;24(07):1686-1691. Doi: 10.1007/s11605-02004592-9

13 Prachand VN, Milner R, Angelos P, et al. Medically Necessary, Time-Sensitive Procedures: Scoring System to Ethically and Efficiently Manage Resource Scarcity and Provider Risk During the COVID-19 Pandemic. J Am Coll Surg 2020;231(02):281-288. Doi: 10.1016/j.jamcollsurg.2020.04.011

14 Campi R, Tellini R, Grosso AA, Amparore D, Mari A, Viola L, et al. Deferring elective urologic surgery during the COVID-19 pandemic: the patients' perspective. Urology 2021;147:21-26

15 Zampolli HC, Rodriguez AR. Laparoscopic and robotic urology surgery during global pandemic COVID19. Int Braz J Urol 2020;46 (Suppl 1):215-221

16 Simonato A, Giannarini G, Abrate A, Bartoletti R, Crestani A, De Nunzio $C$, et al. Clinical pathways for urology patients during the COVID-19 pandemic. Minerva Urologica e Nefrologica - The Italian Journal of Urology and Nephrology 2020;72(03):376-383 